\title{
Relapse of extinguished fear after exposure to a dangerous context is mitigated by testing in a safe context
}

\author{
Travis D. Goode, ${ }^{1}$ Janice J. Kim, ${ }^{2}$ and Stephen Maren ${ }^{1,2}$ \\ ${ }^{1}$ Institute for Neuroscience, Texas A\&M University, College Station, Texas 77843-3473, USA; ${ }^{2}$ Department of Psychology, \\ Texas A\&M University, College Station, Texas 77843-3473, USA
}

\begin{abstract}
Aversive events can trigger relapse of extinguished fear memories, presenting a major challenge to the long-term efficacy of therapeutic interventions. Here, we examined factors regulating the relapse of extinguished fear after exposure of rats to a dangerous context. Rats received unsignaled shock in a distinct context ("dangerous" context) $24 \mathrm{~h}$ prior to auditory fear conditioning in another context. Fear to the auditory conditioned stimulus (CS) was subsequently extinguished either in the conditioning context ("ambiguous" context) or in a third novel context ("safe" context). Exposure to the dangerous context 30 min before a CS retention test caused relapse to the CS in the ambiguous and safe test contexts relative to nonextinguished controls. When rats were tested $24 \mathrm{~h}$ later (with or without short-term testing), rats tested in the ambiguous context continued to exhibit relapse, whereas rats tested in the safe context did not. Additionally, exposure of rats to the conditioning context-in place of the unsignaled shock context-did not result in relapse of fear to the CS in the safe testing context. Our work highlights the vulnerabilities of extinction recall to interference, and demonstrates the importance of context associations in the relapse of fear after extinction.
\end{abstract}

Relapse of extinguished fear is common to behavioral therapies for pathological anxiety (Rachman 1979, 1989; Kehoe and Macrae 1997; Boschen et al. 2009; Dibbets et al. 2013; Vervliet et al. 2013a,b; Bouton 2014; Haaker et al. 2014). This is a pervasive issue: Craske and Mystkowski (2006) suggest that as many as three out of five patients will experience significant relapse of previously extinguished fear. Fortunately, fear reduction and relapse phenomena in humans can be effectively modeled using Pavlovian conditioning and extinction procedures in rats (Bouton 1988; Delgado et al. 2006; Milad et al. 2006; Hofmann 2007; Maren 2011; Milad and Quirk 2012; VanElzakker et al. 2013). Fear conditioning involves the coupling of a neutral, yet detectable, conditioned stimulus ("CS"; e.g., an auditory tone) with a potent, biologically significant unconditioned stimulus ("US"; e.g., unavoidable footshock) (Pavlov 1927; Gunther et al. 1997; Maren 2001, 2005). After conditioning, the CS comes to elicit conditioned fear responses ("CRs"), such as freezing behavior in rats (Bolles 1970; Fanselow 1980, 1994; Sigmundi et al. 1980; Hagenaars et al. 2014). After repeated presentations of the CS alone, the magnitude and frequency of the CR is diminished, a process termed extinction (Pavlov 1927; Konorski 1948; Lolordo and Rescorla 1966; Rescorla 2001; Bouton 2004; Hermans et al. 2006; Chang et al. 2009; Fitzgerald et al. 2014; also see Jones et al. 2013). Standard extinction procedures do not erase the original fear memory; rather extinction represents a new form of learning that inhibits conditioned responding to the aversive CS (Konorski 1967; Bouton 1993; Falls 1998; Maren 2011; also see Myers et al. 2006). Consequently, extinguished fear in humans and other animals is often transient and prone to different forms of fear relapse, including "renewal," "spontaneous recovery," and "reinstatement" (Bouton 2000, 2002, 2014; Ji and Maren 2007; Schiller et al. 2008; Maren 2011; Goode and Maren 2014). Presentation of an extinguished CS outside of the context in

Corresponding author: maren@tamu.edu

Article is online at http://www.learnmem.org/cgi/doi/10.1101/lm.037028.114. which extinction training occurred-whether in a novel or familiar place-can induce "renewal" of fear to the CS (Bouton and King 1983; Bouton and Ricker 1994; Alvarez et al. 2007; Effting and Kindt 2007; Neumann and Longbottom 2008; Polack et al. 2013; Vervliet et al. 2013a; Maren 2014). Fear renewal can also occur if the extinguished CS is encountered during a time in which the animal's interoceptive context is incongruent with the internal state that is associated with extinction (Bouton 1993; Bouton et al. 2006; Maren et al. 2013; Vervliet et al. 2013a,b). For recent reviews on the function of contexts in conditioned and extinguished fear, see Maren et al. (2013) and Urcelay and Miller (2014). With relation to renewal of fear (see Bouton 2002), "spontaneous recovery" is a return of extinguished CR that occurs with the mere passage of time (Pavlov 1927; Baum 1988; Quirk 2002; Rescorla 2004). Finally, reexposure to the US alone after extinction can result in a return of fear responding to the CS, termed "reinstatement" (Pavlov 1927; Rescorla and Heth 1975; Bouton and Bolles 1979; Bouton 1988, 1991; Westbrook et al. 2002; Hermans et al. 2005; Norrholm et al. 2006; Haaker et al. 2014; also see Dirikx et al. 2009).

Recent reports indicate that exposure of rats to cues or contexts that have been independently associated with an aversive US can induce reinstatement. For example, Halladay et al. (2012) have reported that presentation of a nonextinguished CS will reinstate fear to an extinguished CS. Similarly, Morris et al. $(2005 a, b)$ found that brief exposure of rats to a shock-associated context-minutes before presenting an extinguished CS in a separate testing context-reinstated fear to the CS. This fear enhancing effect persisted at least $24 \mathrm{~h}$ following the "dangerous" context

\footnotetext{
(C) 2015 Goode et al. This article is distributed exclusively by Cold Spring Harbor Laboratory Press for the first 12 months after the full-issue publication date (see http://learnmem.cshlp.org/site/misc/terms.xhtml). After 12 months, it is available under a Creative Commons License (Attribution-NonCommercial 4.0 International), as described at http://creativecommons.org/ licenses/by-nc/4.0/.
} 
exposure. These findings have important implications for fear relapse after extinction-like therapies in humans. That is, they suggest that reinstatement can occur not only after an aversive event, but also after exposure of individuals to contexts or cues associated with aversive experiences in the past.

Of course, one factor that is known to influence relapse is the context in which the extinguished CS is experienced. For example, Morris et al. (2005a,b) conditioned, extinguished, and tested rats to an auditory CS in the same context (refer to Experiments 3, 5, 6, and 7 of Morris et al. 2005a, and Experiment 1 in Morris et al. 2005 b). As a result, the test context was "ambiguous" because it had hosted two distinct training experiences: an aversive conditioning episode and a "safe" extinction episode (see Bouton $1988,2002)$. Because contextual information is thought to "set the occasion" for the current meaning of the CS (Holland 1985; Bouton and Swartzentruber 1986; Bouton 1993, 1997; Miller and Escobar 2002), relapse of fear may be more likely in a context that has previously hosted conditioning. By this view, relapse might be thwarted by testing rats in a reliably safe context (e.g., a context that has hosted only extinction training). Consistent with this, Bouton and Swartzentruber (1989) demonstrated that reacquisition of extinguished CR (i.e., a return of CR after pairings of the extinguished CS with the US) was slower in a context that solely hosted extinction training when compared with reacquisition in a novel context or with reacquisition in the original conditioning context (refer to Experiment 2 of Bouton and Swartzentruber 1989; also see Leung et al. 2007). Ultimately, contexts with a history of hosting both conditioning and extinction may interfere with the animal's ability to discriminate between these training episodes (see Bouton and Bolles 1979), thus fostering relapse.

Therefore, in the present experiments, we examined whether the associative history of the test context influences the expression of fear relapse to an extinguished CS in rats. Specifically, we hypothesized that reinstatement of fear would occur in an ambiguous test context that had previously hosted both conditioning and extinction, but not in a "safe" test context that had only predicted the absence of shock (e.g., an extinction-only context). To address these predictions, we first established a "dangerous" shock-associated context (or a "neutral" no-threat context) prior to conditioning and extinction. After extinction, we exposed rats to either the dangerous context (i.e., the relapse trigger) or the neutral context prior to retrieval testing in either an ambiguous or safe context. Retrieval tests were conducted at $30 \mathrm{~min}$ ("short-term") and/or $24 \mathrm{~h}$ ("long-term") after exposure to the dangerous or neutral context. Morris et al. (2005a) reported that relapse was most robust soon after exposure to a dangerous context; we were particularly interested to determine whether testing in a safe context would mitigate relapse soon after exposure to the dangerous context. We also examined whether brief exposure of rats to the conditioning context-in place of the unsignaled shock context-would induce relapse in the safe test context. Overall, our work indicates that relapse of extinguished fear interacts with both the associative history of the testing context and the recency of exposure to the dangerous context. Specifically, shortterm relapse occurred in both test contexts following exposure of rats to the unsignaled shock context, whereas long-term relapse occurred only in the ambiguous context. We observed no relapse of fear in the safe context following exposure of rats to the conditioning context. This work demonstrates the susceptibilities of extinction memories to disruption in the wake of psychological stress, and highlights the importance of context associations in modulating fear responding.

\section{Results}

\section{Experiment la/b: fear relapse in an ambiguous context after exposure to a dangerous context}

We first sought to replicate the findings of Morris et al. (2005a) by determining whether exposure to a dangerous context would cause fear relapse to an extinguished CS. Therefore, in Experiment 1 , we examined whether fear relapse would occur in an ambiguous retrieval context at short- and long-term intervals following exposure of rats to a separate dangerous context (refer to Table 1 for an overview of the experimental design). Data from the extinction and testing sessions are shown in Figure 1. No significant group differences were detected for fear conditioning in any of the following experiments (conditioning data not shown). Mean freezing ( \pm SEM) prior to CS onset for the first extinction session is as shown: DANGER/EXT $=83.6 \% \pm 3.5 \%$, NEUTRAL/EXT $=60.2 \% \pm 7.1 \%, \quad$ DANGER/NoEXT $=68.2 \% \pm$ $4.9 \%, \quad$ NEUTRAL/NoEXT $=64.6 \% \pm 5.9 \%$. Baseline freezing revealed a main effect of exposure assignments $\left[F_{(1,60)}=6.02\right.$; $P<0.05]$. No other group differences were detected for baseline fear for the first extinction session. Overall, rats exhibited robust extinction and significantly decreased their levels of fear by the final block of extinction training (see Fig. 1A, under "Extinction"). This impression was confirmed in a repeated-measures analysis of variance (ANOVA) that revealed a significant main effect of block $\left[F_{(1,60)}=214 ; \quad P<0.0001\right]$. Extinguished rats (EXT) exhibited higher fear after CS onset compared with NoEXT rats (significant block $\times$ extinction interaction $\left.\left[F_{(1,60)}=19.0 ; P<0.0001\right]\right)$. Interestingly, DANGER rats (i.e., DANGER/EXT and DANGER/ NoEXT) were slower to extinguish their freezing behavior. Specifically, we observed a block $\times$ exposure interaction $\left[F_{(1,60)}=6.88\right.$; $P<0.05]$, indicating that DANGER rats were freezing more in the first block of extinction training as compared with NEUTRAL rats. Of course, rats in the DANGER groups received one more footshock than those in the neutral groups, and this

Table 1. Experimental designs

\begin{tabular}{|c|c|c|c|c|c|c|}
\hline \multirow[b]{2}{*}{ EXP. \# } & Phase & \multirow[b]{2}{*}{ Condition } & \multirow[b]{2}{*}{ Extinction (EXT or NoEXT) } & \multirow[b]{2}{*}{ Exposure } & \multirow[b]{2}{*}{ Short-term test } & \multirow[b]{2}{*}{ Long-term test } \\
\hline & $\begin{array}{l}\text { Establish DANGER } \\
\text { or NEUTRAL Context }\end{array}$ & & & & & \\
\hline \multicolumn{7}{|l|}{ AMB } \\
\hline 1a) & $\mathrm{A}+$ or $\mathrm{A}-$ & $\mathrm{BT}+$ & $\mathrm{BT}-$ or $\mathrm{B}-$ & A- & BT - & BT - \\
\hline 1b) & $\mathrm{A}+$ or $\mathrm{A}-$ & $\mathrm{BT}+$ & $\mathrm{BT}-$ or $\mathrm{B}-$ & A- & n.a. & BT- \\
\hline \multicolumn{7}{|l|}{ SAFE } \\
\hline 2a) & $\mathrm{A}+$ or $\mathrm{A}-$ & BT+ & $\mathrm{CT}-$ or $\mathrm{C}-$ & A- & $\mathrm{CT}-$ & $\mathrm{CT}-$ \\
\hline $2 b)$ & $\mathrm{A}+$ or $\mathrm{A}-$ & BT+ & $\mathrm{CT}-$ or $\mathrm{C}-$ & $A-$ & n.a. & $\mathrm{CT}-$ \\
\hline 3) & n.a. & BT+ & $\mathrm{CT}-$ or $\mathrm{C}-$ & $\mathrm{B}-$ or $\mathrm{C}-$ & $\mathrm{CT}-$ & $\mathrm{CT}-$ \\
\hline
\end{tabular}

Experimental designs are read from left to right, with numbers corresponding to Experiments $1-3$.

$(A, B, C)$ experimental contexts, (T) tone CS, (+) US, (-) no US, (n.a.) not applicable, (SAFE) safe testing context, (AMB) ambiguous testing context. 
may have retarded extinction (context fear at baseline may have bolstered CS responding in DANGER rats). Nonetheless, the exposure $\times$ extinction interaction was not reliable across the entirety of extinction training $[F<1.00]$ and no significant differences in the groups were detected for the final block of extinction training.

Twenty-four hours after extinction training, rats were exposed to either a shock-associated context (DANGER) or to a familiar no-threat context (NEUTRAL) for 3 min (reported in Fig. $1 \mathrm{~A}$, under "Exposure"). As expected, the dangerous context itself reliably induced fear. Rats in the dangerous context exhibited significantly higher levels of freezing than rats in the neutral context. This was confirmed in an ANOVA that revealed a significant main effect of exposure $\left[F_{(1,120)}=145 ; P<0.0001\right]$ and a significant exposure $\times$ minute interaction $\left[F_{(1,120)}=6.30 ; P<0.005\right]$. Freezing levels in the exposure chambers did not interact with extinction assignments $[F<1.50]$.

After exposure to the dangerous or neutral contexts, rats in Experiment 1a were tested to the CS in an ambiguous retrieval context at $30 \mathrm{~min}$ and $24 \mathrm{~h}$ after the exposure session (refer to Table 1). As shown in Figure 1B, rats exposed to the "dangerous" context exhibited relapse of extinguished fear, relative to nonextinguished animals or animals exposed to a "neutral" context. An ANOVA revealed a significant exposure $\times$ extinction $\times$ trial interaction $\left[F_{(6,168)}=2.25 ; P<0.05\right]$ and post hoc comparisons $(P<0.05)$ indicated that DANGER/EXT rats exhibited significantly more freezing across trials and days as compared with NEUTRAL/EXT rats. Conversely, DANGER/NoEXT rats were not significantly different from NEUTRAL/NoEXT rats. The test
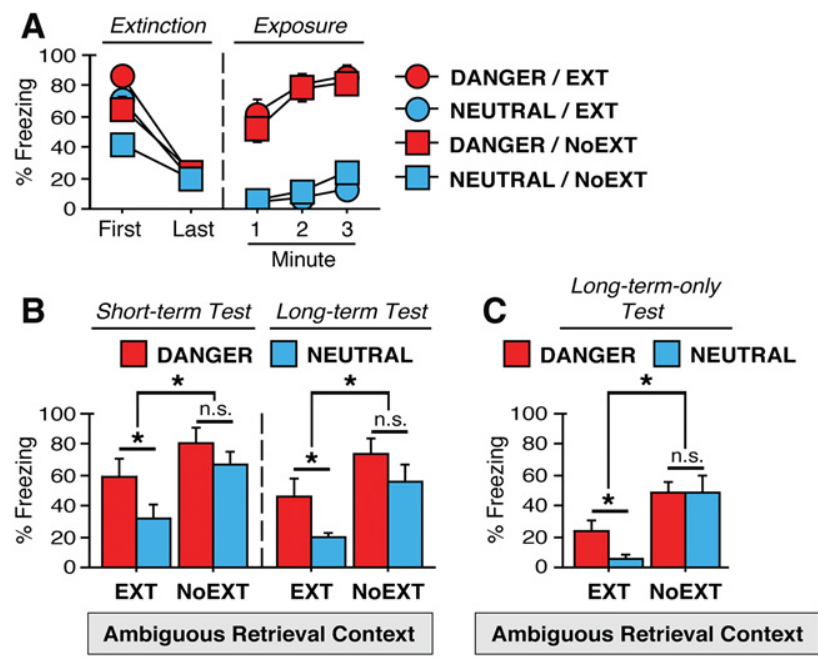

Figure 1. Relapse of extinguished fear in an ambiguous retrieval context at $30 \mathrm{~min}$ and $24 \mathrm{~h}$ after exposure of rats to a dangerous context (Experiment 1$)$. $(A)$ Extinction = mean $( \pm$ SEM) percentage of freezing during the first 15 post-CS intervals (for "EXT" rats; or equivalent for "NoEXT" rats) on the first day of extinction training ("First"), and during the final 15 post-CS intervals on the last day of extinction training ("Last"). Exposure = mean $( \pm$ SEM) percentage of freezing during each minute in the shock-associated context ("DANGER") or no-threat ("NEUTRAL") context prior to CS testing. (B) Short-term test and Long-term test $=$ mean $( \pm S E M)$ percentage of freezing during five post-CS intervals (per test) in the ambiguous retrieval context. Rats were tested to the CS in the ambiguous context at 30 min ("Short-term test") and 24 h ("Long-term test") after the exposure phase (Experiment 1a). (C) Long-term-only test $=$ mean $( \pm$ SEM) percentage of freezing during five post-CS intervals in the ambiguous retrieval context. Rats were tested to the CS at $24 \mathrm{~h}$ postexposure without shortterm testing (Experiment $1 \mathrm{~b}$ ). Asterisks indicate significant differences $(P<0.05)$ for each retention test; (n.s.) nonsignificant comparisons. day $\times$ exposure $\times$ extinction interaction was not reliable $[F<$ 0.50], indicating that relapse of fear in DANGER/EXT rats was apparent for both test sessions. A main effect of test day $\left[F_{(1,168)}=\right.$ 6.12; $P<0.05]$ showed that responding was higher overall for all groups in the short-term test as compared with long-term testing (some extinction of fear is expected over the course of short-term testing). Overall, DANGER rats displayed significantly more fear at both tests compared with NEUTRAL rats (main effect of exposure $\left.\left[F_{(1,168)}=7.18 ; P<0.05\right]\right)$ and nonextinguished controls exhibited more fear at both tests overall as compared with extinguished rats (main effect of extinction $\left[F_{(1,168)}=12.30 ; \quad P<0.005\right]$ ). Baseline context fear prior to CS onset was low $(<30 \%)$ for all groups across both tests (data not shown). Overall, as predicted, data for Experiment 1a suggest that exposure to the dangerous context caused both short- and long-term reinstatement of fear to an extinguished CS.

In Experiment 1b, the procedures were identical to those in Experiment 1a except we omitted the short-term test. This was done to determine whether short-term testing (which is itself an extinction test) might undermine long-term relapse. However, as shown in Figure 1C, the test data mirrored the results from Experiment 1a. Extinguished rats that were exposed to the dangerous context exhibited significantly more fear to the CS than neutral-exposed rats in the long-term test. A repeated-measures ANOVA revealed a significant main effect of exposure for extinguished rats $\left[F_{(1,84)}=8.01 ; P<0.05\right]$ across all trials, and a significant exposure $\times$ trial interaction $\left[F_{(1,84)}=2.22 ; P<0.05\right]$. In contrast, no main effect of exposure was revealed for nonextinguished rats $[F<0.01]$, nor did we find any exposure $\times$ trial interaction for nonextinguished rats $[F<0.50]$. Mean baseline context fear (prior to CS onset) for each group was low in the long-term test ( $<20 \%$ freezing; data not shown). In sum, as expected for Experiment 1, we observed relapse of fear in the ambiguous testing context at $30 \mathrm{~min}$ and $24 \mathrm{~h}$ following exposure of extinguished rats to a dangerous shock-associated context.

\section{Experiment $2 \mathrm{a} / \mathrm{b}$ : no long-term fear relapse in a safe context after exposure to a dangerous context}

The primary objective of Experiment 2 was to determine whether testing rats in a safe (extinction-only) context would blunt fear relapse (refer to Table 1). Mean baseline freezing prior to the first extinction trial is as follows: DANGER/EXT $=45.8 \%(4.4 \%)$, NEUTRAL $/$ EXT $=33.8 \% \quad(7.1 \%), \quad$ DANGER/NoEXT $=59.4 \%$ $(6.1 \%)$, NEUTRAL/NoEXT $=31.6 \%(5.8 \%)$. As in Experiment 1 , we observed a main effect of exposure assignments during this baseline $\left[F_{(1,60)}=6.46 ; P<0.05\right]$; no other significant differences were detected for baseline context fear. Extinction training resulted in a robust suppression of fear (Fig. 2A). This was confirmed by a significant main effect of block in the ANOVA $\left[F_{(1,60)}=85.8 ; P<\right.$ $0.0001])$. EXT rats showed significantly more fear to CS-only presentations compared with the mere exposure of nonextinguished rats to the context (main effect of extinction assignment $\left[F_{(1,60)}=\right.$ 24.0; $P<0.0001]$ ). Consistent with Experiment 1, DANGER rats did not extinguish as rapidly as NEUTRAL rats. A significant exposure $\times$ extinction $\times$ block interaction $\left[F_{(1,60)}=10.0 ; \quad P<\right.$ $0.0001]$ indicated that freezing was higher in the first block of extinction training for DANGER rats. Post hoc comparisons $(P<$ 0.05) revealed that NEUTRAL/NoEXT exhibited significantly less fear compared with all other groups (i.e., DANGER/EXT, DANGER/NoEXT, NEUTRAL/EXT) in the first block. There were no significant differences between the groups in the final extinction block (all group means were $<40 \%$ freezing by the end of extinction).

Twenty-four hours after extinction training, all rats were exposed to either the dangerous or neutral contexts for $3 \mathrm{~min}$ (see 

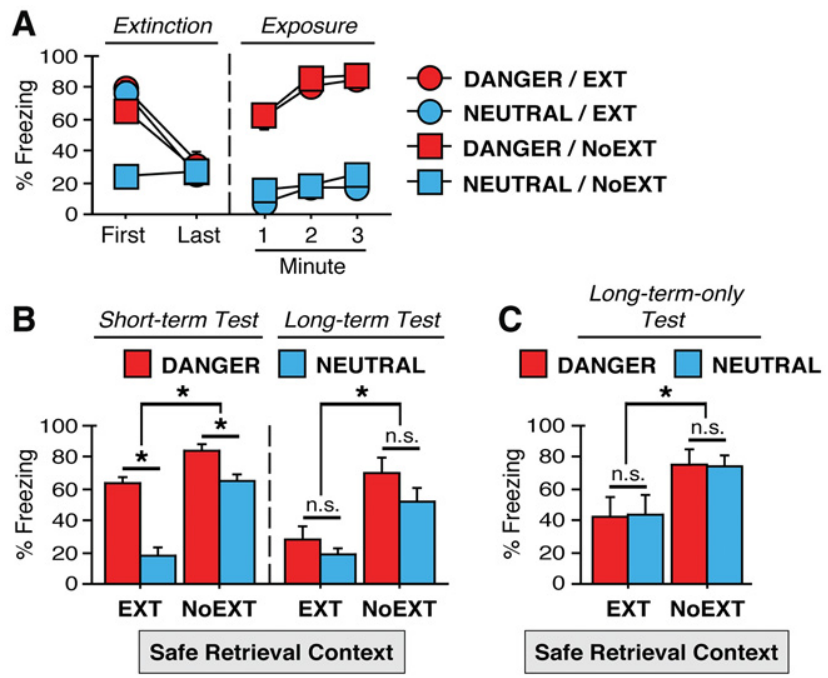

Figure 2. Relapse of fear in a safe retrieval context shortly after exposure to a dangerous context, but no long-term relapse of fear in a safe context (Experiment 2). (A) Extinction = mean $( \pm$ SEM) percentage of freezing during the first 15 post-CS intervals (for "EXT" rats; or equivalent for "NoEXT" rats) on the first day of extinction training ("First"), and during the final 15 post-CS intervals on the last day of extinction training ("Last"). Exposure $=$ mean $( \pm$ SEM) percentage of freezing during each minute in the shock-associated context ("DANGER") or no-threat ("NEUTRAL") context prior to CS testing. (B) Short-term test and Long-term test $=$ mean $( \pm$ SEM) percentage of freezing during five post-CS intervals (per test) in the safe retrieval context. Rats were tested to the CS in the safe context at 30 min ("Short-term test") and $24 \mathrm{~h}$ ("Long-term test") after the exposure phase (Experiment 2a). (C) Long-term-only test $=$ mean $( \pm$ SEM) percentage of freezing during five post-CS intervals in the safe retrieval context. Rats were tested to the CS at $24 \mathrm{~h}$ postexposure without short-term testing (Experiment $2 \mathrm{~b}$ ). Asterisks indicate significant differences $(P<0.05)$ for each retention test; (n.s.) nonsignificant comparisons.

Fig. 2A, under "Exposure"). As in Experiment 1, DANGER rats exhibited significantly more fear in the dangerous context as compared with NEUTRAL rats in the neutral context for Experiment 2. This impression was confirmed in an ANOVA that revealed a significant main effect of exposure $\left[F_{(1,120)}=252 ; P<0.0001\right]$ and a significant minute $\times$ exposure interaction $\left[F_{(2,120)}=4.49 ; P<\right.$ $0.05]$; these effects did not interact with extinction history $[F<$ $1.70]$, Overall, the dangerous context reliably induced fear whereas the neutral context did not.

For rats in Experiment 2a, subjects received a retention test in the safe extinction context at $30 \mathrm{~min}$ and $24 \mathrm{~h}$ following the exposure phase (Fig. 2B). Similar to Experiment 1a, rats exposed to the "dangerous" context prior to the retrieval test exhibited fear relapse to the extinguished CS, despite the fact that testing occurred in the extinction context (i.e., a safe context). However, unlike Experiment 1, testing in the safe context mitigated relapse of fear during the long-term test. These impressions were confirmed in an ANOVA that revealed a significant exposure $\times$ extinction $\times$ day interaction $\left[F_{(1,168)}=5.18 ; P<0.05\right]$. Post hoc comparisons $(P<0.005)$ indicated that DANGER/EXT rats exhibited significantly more fear in the short-term test-but not the long-term test-as compared with NEUTRAL/EXT rats. Similar to Experiment 1a, responding was higher across groups in the short-term test as compared with long-term testing (main effect of test day $\left.\left[F_{(1,168)}=15.2 ; P<0.001\right]\right)$, and freezing was higher in NoEXT rats across trials when compared with EXT rats (main effect of extinction $\left.\left[F_{(1,168)}=49.1 ; P<0.0001\right]\right)$. Additionally, DANGER rats showed greater levels of fear overall as compared with
NEUTRAL rats (main effect of exposure $\left[F_{(1,168)}=18.3 ; P<\right.$ 0.0005]). Unlike Experiment 1a, DANGER/NoEXT rats exhibited significantly more fear in the short-term test as compared with NEUTRAL/NoEXT rats $(P<0.05)$. These results may reflect the pattern we observed for DANGER/NoEXT rats in the early phases of extinction to the CS, and may be a unique feature of testing in the safe context (NoEXT rats did not differ across exposure assignments in any of the long-term tests of this report). Overall, the ANOVA on the test data in Experiment 2a suggests that a general increase in fear in rats in the DANGER condition cannot account for the later relapse of fear in extinguished animals. Baseline context fear for each group was low $(<30 \%)$ prior to CS onset in each test. To summarize, testing in a safe context did not prevent shortterm relapse of extinguished fear, but did mitigate the long-term reinstatement of fear.

Additionally, this outcome was confirmed in Experiment 2b, in which rats were submitted to identical procedures except that the short-term test was omitted. As shown in Figure 2C, there was no relapse of extinguished fear in the safe retrieval context $24 \mathrm{~h}$ after exposure of rats to the DANGER context. There was only a main effect of extinction $\left[F_{(1,168)}=8.96 ; P<0.01\right]$ in the ANOVA, indicating that nonextinguished rats exhibited significantly more fear at test than extinguished subjects. In sum, testing in a safe context prevented the long-term relapse of fear.

\section{Experiment 3: no relapse of fear in a safe test context following exposure to the conditioning context}

In Experiments 1 and 2, we utilized a separate shock context to serve as the dangerous context for the exposure phase prior to $\mathrm{CS}$ testing. However, the conditioning procedure itself yields a dangerous context (the conditioning context). Thus, the goal of Experiment 3 was to examine whether brief exposure to the conditioning context could induce relapse (see Table 1). Based on the results we obtained in Experiment 2, we expected the potential for relapse to be weak in Experiment 3 (at least in the long-term test). For the exposures in Experiment 3, we exposed rats either to the conditioning chamber (DANGER) or to the extinction chamber (SAFE) 30 min prior to a retention test back in the extinction chamber (long-term testing occurred $24 \mathrm{~h}$ later).

For Experiment 3, baseline freezing prior to the first extinction trial was not different among the groups (a trending but nonsignificant main effect of exposure assignments was observed $[F<4.00]):$ DANGER $/$ EXT $=30.7 \%(10.0 \%)$, SAFE $/ \mathrm{EXT}=48.2 \%$ $(10.7 \%), \quad$ DANGER/NoEXT $=18.5 \% \quad(5.6 \%), \quad$ SAFE $/$ NoEXT $=$ $37.4 \%(9.4 \%)$. As shown in Figure 3A, extinction resulted in a suppression of freezing behavior. As expected, we observed a main effect of extinction assignment $\left[F_{(1,28)}=16.5, P<0.0005\right]$ and a significant block $\times$ extinction interaction $\left[F_{(1,28)}=13.7, \quad P<\right.$ 0.001 ] such that EXT rats exhibited significantly higher levels of freezing in the first block of extinction training. We observed a main effect of exposure $\left[F_{(1,28)}=4.99, P<0.05\right]$, however this effect was carried primarily by SAFE rats (and not DANGER rats; unlike Experiments 1 and 2) in the first block of the extinction phase. Groups did not significantly differ by the final block of the analyses (group means were $<30 \%$ freezing by the final block of extinction), so we proceeded to the next phase of behavioral training.

Twenty-four hours after extinction, rats were exposed to either the conditioning context (DANGER) or the extinction context (SAFE) for 3 min (see Fig. 3A, under "Exposure"). As expected, DANGER rats exhibited significantly more fear in the conditioning context as compared with SAFE rats in the extinction context (main effect of exposure $\left[F_{(1,56)}=35.0 ; P<0.0001\right]$ ). Extinction history did not interact with this effect $[F<0.50]$. A main effect of trial indicated that rats increased in freezing along the course of the exposure session $\left[F_{(2,56)}=5.32 ; P<0.01\right]$. No other 

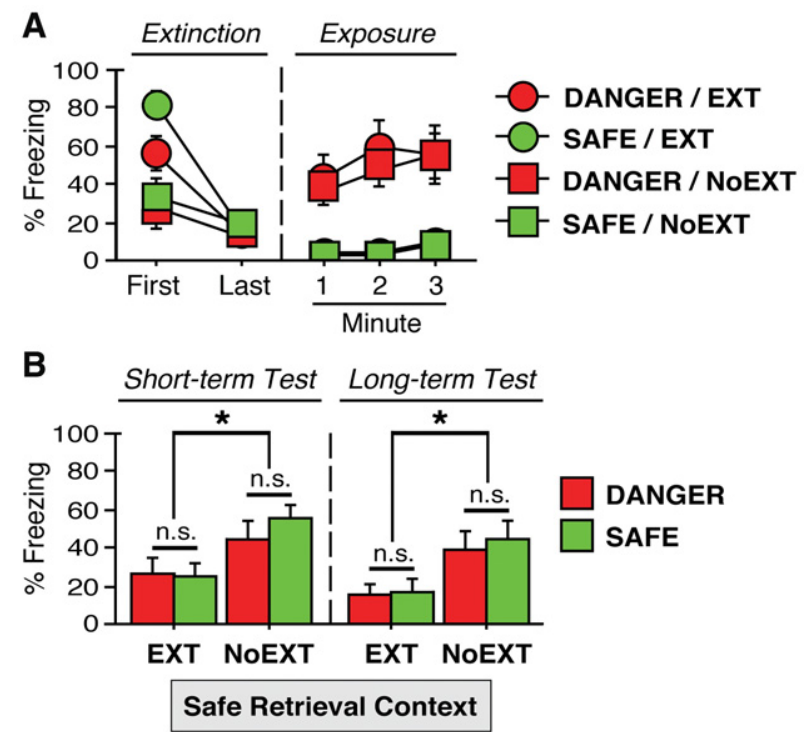

Figure 3. No relapse of fear in a safe retrieval context following exposure of rats to the conditioning context (Experiment 3). (A) Extinction = mean ( \pm SEM) percentage of freezing during the first 15 post-CS intervals (for "EXT" rats; or equivalent for "NoEXT" rats) on the first day of extinction training ("First"), and during the final 15 post-CS intervals on the last day of extinction training ("Last"). Exposure $=$ mean $( \pm$ SEM) percentage of freezing during each minute of the exposure to the conditioning context ("DANGER") or extinction context ("SAFE") prior to CS testing. (B) Short-term test and Long-term test $=$ mean $( \pm$ SEM) percentage of freezing during five post-CS intervals (per test) in the safe retrieval context. All rats were tested to the CS in the safe context 30 min ("Short-term test") and $24 \mathrm{~h}$ ("Long-term test") after the exposure phase. Asterisks indicate significant differences $(P<0.05)$ for each retention test; (n.s.) nonsignificant comparisons.

significant differences were detected for the exposure phase. Overall, the conditioning chamber reliably induced freezing in subjects.

Thirty minutes and $24 \mathrm{~h}$ following the exposure session, all rats were tested to the CS in the "safe" extinction context. Despite high levels of fear in the conditioning context, no relapse of fear was observed for either test in the safe context (Fig. 3B). In other words, in contrast to Experiment 2a, we did not observe short-term relapse of fear in the safe context. Specifically, the ANOVA did not reveal a reliable exposure $x$ extinction $\times$ day interaction $[F<0.50]$, nor was there a significant trial $\times$ exposure $\times$ extinction interaction $[F<1.00]$ across the two test sessions. A main effect of extinction $\left[F_{(1,168)}=12.1 ; P<0.005\right]$ showed that nonextinguished rats froze more at test than extinguished rats, which was expected. A main effect of test day $\left[F_{(1,168)}=4.44\right.$; $P<0.05$ ] indicated that responding was greater overall on the first day of testing, but some extinction of fear to the CS is expected across test sessions. Group means at baseline were $<30 \%$ freezing per test in Experiment 3. Collectively, these analyses indicate that although exposure to the conditioning context generated fear, it did not drive relapse of fear at either time point in the safe test context. In sum, Experiment 3 indicates that fear relapse is completely mitigated in a safe test context when exposure to the conditioning context serves as aversive trigger.

\section{Discussion}

In the present study, we have examined contextual factors regulating the relapse of previously extinguished fear. In agreement with
Morris et al. (2005a), we have shown that brief exposure of rats to an unsignaled shock-associated context (i.e., a dangerous context) promotes fear relapse to an extinguished CS. Importantly, we have extended on these results by showing that the associative history of the retrieval context influences fear relapse: long-term fear relapse was attenuated in a safe (extinction-only) retrieval context, but not in an ambiguous retrieval context (i.e., an extinction context that had previously hosted conditioning). The safe retrieval context did not prevent relapse altogether, insofar as short-term relapse occurred regardless of where the extinguished $\mathrm{CS}$ was tested. Moreover, brief exposure of rats to the conditioning context did not result in relapse of fear in any of the retrieval tests in the safe context. Our findings provide new insights into the factors regulating reinstatement of fear after exposure of animals to aversive stimuli. In particular, strategies aimed at preventing relapse of fear may need to consider the context in which fearful stimuli are likely to be encountered after therapy. Indeed, safe contexts appear to promote the retention of extinction relative to contexts with a history of both aversive and safe experiences.

Previous research indicates that reinstatement of fear to a discrete CS is driven by context-US associations established in the reinstatement context (Bouton and Bolles 1979; Bouton and King 1983; Bouton 1984; Wilson et al. 1995; Frohardt et al. 2000). In these studies, reinstatement is context-dependent; it only occurs in the context in which the US is delivered. In contrast to these findings, results from our work and Morris et al. (2005a,b) indicate that reinstatement is not always context-dependent. For example, in the present experiments, short-term reinstatement of conditioned freezing to the CS occurred in a context that was never associated with shock (the safe extinction context). Reinstatement under these conditions may be due to mediated conditioning; the CS may have retrieved a context-US association that promoted fear (Holland 1990; Westbrook et al. 2002). However, our current work also indicates that long-term reinstatement of fear (after exposure to a dangerous place) is susceptible to contextual control; it only occurred in a context in which the US had been experienced. In this case, the conditioning context may have encouraged recall of the CS-US memory encoded during the conditioning phase, whereas the extinction context encouraged recall of the CS-"no US" memory (Bouton 1993, 2002; Vansteenegen et al. 2006; also see Bouton et al. 2004). Nevertheless, retrieval cues for extinction training are not always sufficient to prevent relapse (e.g., in short-term reinstatement). For example, previous work has shown that retrieval cues for extinction do not always suppress fear renewal (Dibbets et al. 2008, 2013).

An alternative explanation for the reinstatement of extinguished fear in our study is that it may reflect renewal brought about by a shift in the interoceptive context in the wake of exposure to a dangerous place (Bouton et al. 2006). That is, extinction training reduces levels of stress and fear; this low-fear state may become an important interoceptive context that helps regulate the expression of the extinction memory. If rats are returned to the extinction context in a state of high stress following fear induction (such as after exposure to a dangerous context), then the animal may experience the extinguished CS outside of the "safe" interoceptive context associated with extinction training. Consistent with this idea, a reduction in physiological arousal (via systemic administration of the $\beta$-adrenoceptor antagonist, propranolol) has been shown to prevent relapse following exposure to a dangerous context (Morris et al. 2005b). A shift in interoceptive context might also explain long-term reinstatement insofar as exposure to the dangerous context-at least the unsignaled shock contextmay produce a long-lasting stress response. Relatedly, it is conceivable that exposure to the dangerous context either strengthens the fear memory (a form of reconsolidation) or impairs the retention of the extinction memory (Izquierdo et al. 2006; 
Miracle et al. 2006; Holmes and Wellman 2009; Knox et al. 2012; Deschaux et al. 2013; Hamacher-Dang et al. 2013; Raio et al. 2014; also see Siette et al. 2014). Both of these effects would promote expression of the fear memory, although neither of these explanations allow for the context-dependent expression of reinstatement during the long-term test. On a final note, relapse of fear may also depend on the robustness of the reinstating trigger. For example, we did not observe relapse of fear following exposure of rats to the conditioning context, however this context appeared to induce less freezing behavior when compared with the exposure of rats to the unsignaled shock contexts of Experiments 1 and 2. The safe context may have been able to mitigate relapse in Experiment 3 because rats were not as stressed as in Experiments 1 and 2. Rats did not receive any additional footshocks beyond conditioning in Experiment 3, which may factor in to the expression of relapse.

In conclusion, the present results reveal that mere exposure to a dangerous context promotes the reinstatement of conditioned fear to an extinguished CS. This effect was contextdependent, at least with respect to time: long-term reinstatement only occurred in test context that had previously been associated with shock and was minimal in an extinction context in which shock had never been delivered. These results suggest that the associative history of the retrieval context is an important determinant of reinstatement of extinguished fear.

\section{Materials and Methods}

\section{Subjects}

Subjects were 160 male Long Evans (Blue Spruce) rats from Harlan Laboratories (Houston, TX, USA). $N=32$ at each test (Experiments $1 \mathrm{a}, 1 \mathrm{~b}, 2 \mathrm{a}, 2 \mathrm{~b}$, and 3 ), with an equal number of subjects per group for all phases of training. All rats were $8 \mathrm{wk}$ of age and weighed 200-250 g upon arrival at the vivarium. All rats were individually housed in clear plastic cages on a rotating cage rack (Animal Care Systems, Inc.). Experimental group assignments were randomized for homecage position in the vivarium. Rats were given free access to water and standard rat chow; sawdust served as cage bedding. Clean homecages were provided for the rats once a week, with behavioral testing occurring on separate days from the cage changings. Rats were kept on a fixed lightdark schedule (14 h of light and $10 \mathrm{~h}$ of darkness per day; lights on at 7:00 a.m. each day) with all handling and behavioral testing occurring during the illuminated period for the rats. Experimenters handled rats for $1 \mathrm{~min}$ a day for $5 \mathrm{~d}$ prior to the start of any behavioral testing. Experimenters (male and female) were the same across all experiments. The Institutional Animal Care and Use Committee approved all behavioral procedures.

\section{Behavioral apparatus}

Rats were trained and tested within 16 identical rodent observation cages $(30 \times 24 \times 21 \mathrm{~cm}$; MED Associates, Inc. $)$ comprised of aluminum and Plexiglas. These cages are evenly distributed within two separate testing rooms in the laboratory (Room 1 and 2). The test cage floor is lined with 19 stainless steel rods $(4 \mathrm{~mm}$ in diameter) spaced $1.5 \mathrm{~cm}$ apart (from center to center). A shock source and solid-state grid scrambler (MED Associates, Inc.) delivered footshock (unconditioned stimulus; US) to the cage floor. A speaker attached to the testing cage provided the auditory conditioned stimulus (CS). Within each observation chamber, a small fan provided background noise $(\sim 70 \mathrm{~dB})$. A metal pan beneath the grid floor collected animal waste. Of note, $15 \mathrm{~W}$ bulbs provided lighting within each chamber as appropriate for the context (see below). Testing cages rested upon load-cell platforms, which respond to cage displacement as a result of motor activity of the subject. A load-cell amplifier sends platform activity to Threshold Activity software (MED Associates, Inc.). Load-cell activity values $(-10$ to $+10 \mathrm{~V})$ are digitized into absolute values within the Threshold Activity software; these values are multiplied by 10 to yield a range of activity of $0-100$ (higher values indicate higher levels of cage displacement). Load-cell activity is digitized at $5 \mathrm{~Hz}$, such that a single observation of load-cell activity is assessed every $200 \mathrm{msec}$ (i.e., 300 observations per rat per minute). For all experiments, freezing behavior (i.e., immobility aside from that which is necessary for breathing) was defined as digitized load-cell values of $\leq 10$ for two sequential seconds or longer (i.e., rats were only considered to be freezing if immobile for two or more seconds). Each load-cell is calibrated prior to the start of behavior to ensure optimal detection of motor activity and freezing behavior. Additionally, all phases of behavioral training and testing were visually recorded from above the animals, as visible through the clear Plexiglas ceilings of the testing cages.

Contexts were made distinct by manipulating the light levels of the testing rooms, the texture of the cage floors, and the odors within the testing cages. Specifically, "Context A" consisted of ammonium hydroxide odor $(50 \mathrm{~mL}$ of $1 \%$ ammonium hydroxide poured into the metal tray beneath the cage), testing cage lights were off, red room lights were on (white room lights were off), cage fans were off, cupboard doors of the testing chambers were closed, and subjects were shuttled in black transport boxes to and from the behavior room (Room 1). "Context B" consisted of acetic acid odor $(50 \mathrm{~mL}$ of $1.5 \%$ acetic acid solution in the pans beneath the cage), with cage lights off, white room lights on (red room lights off), background fans on, cupboard doors open, and clear plastic cages (with sawdust bedding) for transportation of subjects. Context B utilized Room 2. "Context C" used ethanol odor (80\% ethanol solution), cage lights were on, red room lights were on (white room light were off), background fans were on, solid plastic floors were placed over the grid floors of the testing cage, and solid white plastic boxes were used for transport. Context $\mathrm{C}$ utilized Room 2. Use of the solid plastic floors does not impair the acquisition of behavioral data. These contexts were identical across all experiments, however solid white plastic boxes were utilized to transport subjects for Context B in Experiment 1. Testing chambers were cleaned with water and wiped down with paper towels that were dipped in context odor before each behavioral squad. The steel grid floors were dried before the start of any behavior. Additionally, experimental groups were randomly assigned to a testing chamber, which was unique to each context (subjects were placed back in the same testing chamber for the same context).

\section{Procedure}

Experiment $1 a / b$

Rats in Experiment 1 were randomly assigned to an "exposure" group (DANGER or NEUTRAL) and an "extinction" group (EXT or NoEXT) prior to the start of behavioral training. Rats (counterbalanced by group assignments) were either tested to the CS in the ambiguous retrieval context at $30 \mathrm{~min}$ and $24 \mathrm{~h}$ (short- and longterm testing) following postextinction exposure to the dangerous or neutral context (Experiment 1a), or rats were tested at $24 \mathrm{~h}$ without short-term testing following the exposure phase (Experiment 1b). We performed all phases of behavioral training during the same window of time for each day. On the first day of behavioral training in Experiment 1, subjects (in squads of eight) were transported from the vivarium and placed in a distinct context for $4 \mathrm{~min}$ (Context A), with an unsignaled footshock ( $2 \mathrm{sec}, 1 \mathrm{~mA}$ ) delivered $3 \mathrm{~min}$ into the exposure (DANGER rats) or rats were merely exposed to Context A for equal duration (NEUTRAL rats). NEUTRAL rats were counterbalanced by extinction assignment and in separate squads from DANGER rats on the first day of behavioral training (data from the first day of training not shown). Twenty-four hours later, all subjects underwent auditory fear conditioning in Context $\mathrm{B}$, consisting of five tone, conditioned stimulus (CS; $10 \mathrm{sec}, 2 \mathrm{kHz}, 80 \mathrm{~dB}$ tone)-footshock, unconditioned stimulus (US; $2 \mathrm{sec}, 1 \mathrm{~mA}$ ) pairings. The US onset occurred at the termination of the $10 \mathrm{sec}$ CS. CS-US pairings were spaced along 1-min intervals, beginning 3 min after placing subjects in the chambers. Subjects remained in the test chambers 
for 1 min following the final CS-US pairing. All conditioning squads were counterbalanced for group assignment. Freezing (\%) for conditioning was analyzed along six trials: one for baseline activity and five more trials for each minute following CS-US pairings (conditioning data not shown). Twenty-four hours after conditioning, rats underwent extinction to the CS (EXT rats) in the conditioning context ("ambiguous") or mere exposure to conditioning context for equal duration (NoEXT rats). Specifically, following $3 \mathrm{~min}$ of acclimation to Context $\mathrm{B}$, extinction training consisted of 2-3 d of 45 CS-only presentations (10 sec, $2 \mathrm{kHz}$, $80 \mathrm{~dB}$ tone), separated by 30 -sec post-CS intervals. Subjects remained in Context B for $3 \mathrm{~min}$ following the final CS alone presentation. For NoEXT rats, subjects were exposed to Context $\mathrm{B}$ for an equal duration of time as for EXT rats, but without CS-only presentations. Groups were counterbalanced by exposure assignments. To efficiently represent extinction data across multiple days of training, freezing behavior was analyzed across two block trials: one block for mean freezing (\%) during the first 15 post-CS intervals (or equivalent for NoEXT rats), and a second block for the final 15 post-CS intervals on the final day of extinction. Twenty-four hours after extinction training, all rats were exposed for $3 \mathrm{~min}$ to Context A. Rats were immediately returned to their homecages following the exposures (one trial per minute for the analyses). For rats assigned to short-term testing (Experiment 1a), subjects were brought back to the laboratory to be tested to the CS in Context B at 30 min following the exposures. Rats were given $3 \mathrm{~min}$ of acclimation to the testing context before the onset of five CS-only presentations, spaced by 30 sec post-CS intervals. Rats remained in the testing chamber for 3 min following the final tone presentation. In turn, each day of testing comprised of seven trials for the overall analyses: one trial for freezing at baseline, five trials for each of the 30-sec post-CS intervals, and a final trial for behavior during the remaining time in the test chamber. Twenty-four hours after short-term testing (or $24 \mathrm{~h}$ after the exposure phase without short-term testing; i.e., long-term-only testing [Experiment $1 \mathrm{~b}]$ ), all rats underwent testing to the CS as described for short-term testing.

\section{Experiment $2 a / b$}

With a novel cohort of rats, we established a dangerous or neutral context (Context A) on the first day of training for Experiment 2. DANGER rats experienced a $2 \mathrm{sec}, 1 \mathrm{~mA}$ unsignaled footshock at 3 min into a 4-min exposure in Context A; NEUTRAL rats were merely acclimated to Context A for equal duration (data not shown). Twenty-four hours later, all rats were fear conditioned to an auditory CS in Context B as described for Experiment 1. Twenty-four hours after auditory fear conditioning, rats experienced either CS extinction (EXT rats) or mere exposure to Context $\mathrm{C}$ (NoEXT rats) over the course of $2-3 \mathrm{~d}$ (counterbalanced by exposure assignments). Extinction in Experiment 2 was analyzed as described in Experiment 1. Twenty-four hours after extinction training, all rats were exposed to Context A for 3 min then returned to their homecages for either $30 \mathrm{~min}$ (short-term testing; Experiment 2a) or $24 \mathrm{~h}$ (long-term-only testing; Experiment 2b). Testing in Experiment 2 (both short- and long-term) followed the same procedures for behavior (and analyses, where appropriate) as described for Experiment 1, except rats were tested in Context C, which served as the "safe" context by our terms.

\section{Experiment 3}

Untrained subjects in Experiment 3 underwent fear conditioning in Context B on the first day of behavioral training, without the prior establishment of a separate dangerous or neutral context. Fear conditioning in Experiment 3 was procedurally identical to Experiments 1 and 2 (data not shown). Extinction to the CS (EXT rats) occurred over $2 \mathrm{~d}$ in Context $\mathrm{C}$ (analyses were identical to Experiments 1 and 2). Mere exposure for NoEXT rats occurred in Context $\mathrm{C}$ for equal duration. Twenty-four hours after the extinction phase, rats were exposed to either the conditioning context (Context B) for 3 min (DANGER rats), or the extinction context (Context C) for 3 min (SAFE rats). Rats were returned to the vivarium immediately after the exposure phase. Thirty minutes later, all rats were tested to the CS in Context C. An identical test occurred $24 \mathrm{~h}$ later.

\section{Data analysis}

Freezing behavior served as the index of fear throughout all phases of the study. Freezing behavior was defined as the percentage of total time spent immobile during each trial or block of trials as indicated above. All data were analyzed with ANOVAs followed by post hoc comparisons (Fisher's Protected Least Significant Difference test) after a significant omnibus $F$-ratio. No rats were excluded from the analyses.

\section{Acknowledgments}

This work was funded by a grant from the National Institutes of Health (R01MH065961) to S.M.

\section{References}

Alvarez RP, Johnson L, Grillon C. 2007. Contextual-specificity of short-delay extinction in humans: renewal of fear-potentiated startle in a virtual environment. Learn Mem 14: 247-253.

Baum M. 1988. Spontaneous recovery from the effects of flooding (exposure) in animals. Behav Res Ther 26: 185-186.

Bolles RC. 1970. Species-specific defense reactions and avoidance learning. Psychol Rev 77: 32-34.

Boschen MJ, Neumann DL, Waters AM. 2009. Relapse of successfully treated anxiety and fear: theoretical issues and recommendations for clinical practice. Aust N Z J Psychiatry 43: 89-100.

Bouton ME. 1984. Differential control by context in the inflation and reinstatement paradigms. J Exp Psychol Anim Behav Process 10: $56-74$.

Bouton ME. 1988. Context and ambiguity in the extinction of emotional learning: implications for exposure therapy. Behav Res Ther 26: $137-149$.

Bouton ME. 1991. Context and retrieval in extinction and in other examples of interference in simple associative learning. In Current topics in animal learning: brain, emotion, and cognition (ed. Dachowski L, Flaherty CF), pp. 25-53. Erlbaum, Hillsdale.

Bouton ME. 1993. Context, time, and memory retrieval in the interference paradigms of Pavlovian learning. Psychol Bull 114: 80-99.

Bouton ME. 1997. Signals for whether versus when an event will occur. In Learning, motivation, and cognition: the functional behaviorism of Robert C. Bolles (ed. Bouton ME, Fanselow MS), pp. 385-409. American Psychological Association, Washington, DC.

Bouton ME. 2000. A learning theory perspective on lapse, relapse, and the maintenance of behavior change. Health Psychol 19: 57-63.

Bouton ME. 2002. Context, ambiguity, and unlearning: sources of relapse after behavioral extinction. Biol Psychiatry 52: 976-986.

Bouton ME. 2004. Context and behavioral processes in extinction. Learn Mem 11: 485-494.

Bouton ME. 2014. Why behavior change is difficult to sustain. Prev Med 68C: $29-36$.

Bouton ME, Bolles RC. 1979. Role of conditioned contextual stimuli in reinstatement of extinguished fear. J Exp Psychol Anim Behav Process 5: $368-378$.

Bouton ME, King DA. 1983. Contextual control of the extinction of conditioned fear: tests for the associative value of the context. J Exp Psychol Anim Behav Process 9: 248-265.

Bouton ME, Ricker ST. 1994. Renewal of extinguished responding in a second context. Anim Learn Behav 22: 317-324.

Bouton ME, Swartzentruber D. 1986. Analysis of the associative and occasion-setting properties of contexts participating in a Pavlovian discrimination. J Exp Psychol Anim Behav Process 12: 333-350.

Bouton ME, Swartzentruber D. 1989. Slow reacquisition following extinction: context, encoding, and retrieval mechanisms. J Exp Psychol Anim Behav Process 15: 43-53.

Bouton ME, Woods AM, Pineño O. 2004. Occasional reinforced trials during extinction can slow the rate of rapid reacquisition. Learn Motiv 35: $371-390$.

Bouton ME, Westbrook RF, Corcoran KA, Maren S. 2006. Contextual and temporal modulation of extinction: behavioral and biological mechanisms. Biol Psychiat 60: 352-360.

Chang CH, Knapska E, Orsini CA, Rabinak CA, Zimmerman JM, Maren S. 2009. Fear extinction in rodents. Curr Protoc Neurosci Chapter 8: Unit 8.23 . 
Craske MG, Mystkowski JL. 2006. Exposure therapy and extinction: clinical studies. In Fear and learning: from basic processes to clinical implication (ed. Craske MG, Hermans D, Vansteenwegen D), pp. 217-233. American Psychiatric Association, Washington, DC.

Delgado MR, Olsson A, Phelps EA. 2006. Extending animal models of fear conditioning to humans. Biol Psychol 73: 39-48.

Deschaux O, Zheng X, Lavigne J, Nachon O, Cleren C, Moreau JL, Garcia R. 2013. Post-extinction fluoxetine treatment prevents stress-induced reemergence of extinguished fear. Psychopharmacology (Berl) 225: 209-216.

Dibbets P, Havermans R, Arntz A. 2008. All we need is a cue to remember: the effect of an extinction cue on renewal. Behav Res Ther 46: 1070-1077.

Dibbets P, Moor C, Voncken MJ. 2013. The effect of a retrieval cue on the return of spider fear. J Behav Ther Exp Psychiatry 44: 361-367.

Dirikx T, Vansteenwegen D, Eelen P, Hermans D. 2009. Non-differential return of fear in humans after a reinstatement procedure. Acta Psychol (Amst) 130: 175-182.

Effting M, Kindt M. 2007. Contextual control of human fear associations in a renewal paradigm. Behav Res Ther 45: 2002-2018.

Falls WA. 1998. Extinction: a review of theory and the evidence suggesting that memories are not erased without reinforcement. In Learning and behavior therapy (ed. O'Donohue W), pp. 205-229. Allyn and Bacon, Boston.

Fanselow MS. 1980. Conditioned and unconditional components of post-shock freezing. Pavlov J Biol Sci 15: 177-182.

Fanselow MS. 1994. Neural organization of the defensive behavior system responsible for fear. Psychon Bull Rev 1: 429-438.

Fitzgerald PJ, Seemann JR, Maren S. 2014. Can fear extinction be enhanced? A review of pharmacological and behavioral findings. Brain Res Bull 105: $46-60$.

Frohardt RJ, Guarraci F, Bouton ME. 2000. The effects of neurotoxic hippocampal lesions on two effects of context after extinction. Behav Neurosci 114: $227-240$.

Goode TD, Maren S. 2014. Animal models of fear relapse. ILAR J 55: $246-258$.

Gunther LM, Miller RR, Matute H. 1997. CSs and USs: what's the difference? J Exp Psychol Anim Behav Process 23: 15-30.

Haaker J, Golkar A, Hermans D, Lonsdorf TB. 2014. A review on human reinstatement studies: an overview and methodological challenges. Learn Mem 21: 424-440.

Hagenaars MA, Oitzl M, Roelofs K. 2014. Updating freeze: aligning animal and human research. Neurosci Biobehav Rev 47C: 165-176.

Halladay LR, Zelikowsky M, Blair HT, Fanselow MS. 2012. Reinstatement of extinguished fear by an unextinguished conditional stimulus. Front Behav Neurosci 6: 18.

Hamacher-Dang TC, Uengoer M, Wolf OT. 2013. Stress impairs retrieval of extinguished and unextinguished associations in a predictive learning task. Neurobiol Learn Mem 104: 1-8.

Hermans D, Dirikx T, Vansteenwegen D, Baeyens F, Van den Bergh O, Eelen P. 2005. Reinstatement of fear responses in human aversive conditioning. Behav Res Ther 43: 533-551.

Hermans D, Craske MG, Mineka S, Lovibond PF. 2006. Extinction in human fear conditioning. Biol Psychiatry 60: 361-368.

Hofmann SG. 2007. Enhancing exposure-based therapy from a translational research perspective. Behav Res Ther 45: 1987-2001.

Holland PC. 1985. Conditioned inhibition in serial and simultaneous feature negative discriminations. In Information processing in animals (ed. Miller RR, Spear NE), pp. 267-297. Erlbaum, Hillsdale.

Holland PC. 1990. Event representation in Pavlovian conditioning: image and action. Cognition 37: 105-131.

Holmes A, Wellman CL. 2009. Stress-induced prefrontal reorganization and executive dysfunction in rodents. Neurosci Biobehav Rev 33: $773-783$.

Izquierdo A, Wellman CL, Holmes A. 2006. Brief uncontrollable stress causes dendritic retraction in infralimbic cortex and resistance to fear extinction in mice. J Neurosci 26: 5733-5738.

Ji J, Maren S. 2007. Hippocampal involvement in contextual modulation of fear extinction. Hippocampus 17: 749-758.

Jones CE, Ringuet S, Monfils MH. 2013. Learned together, extinguished apart: reducing fear to complex stimuli. Learn Mem 20: 674-685.

Kehoe EJ, Macrae M. 1997. Savings in animal learning: implications for relapse and maintenance after therapy. Behav Ther 28: 141-155.

Knox D, George SA, Fitzpatrick CJ, Rabinak CA, Maren S, Liberzon I. 2012. Single prolonged stress disrupts retention of extinguished fear in rats. Learn Mem 19: 43-49.

Konorski J. 1948. Conditioned reflexes and neuron organization. Cambridge University Press, Cambridge.

Konorski J. 1967. Integrative activity of the brain. University of Chicago Press, Chicago.
Leung HT, Bailey GK, Laurent V, Westbrook RF. 2007. Rapid reacquisition of fear to a completely extinguished context is replaced by transient impairment with additional extinction training. J Exp Psychol Anim Behav Process 33: 299-313.

Lolordo VM, Rescorla RA. 1966. Protection of the fear-eliciting capacity of a stimulus from extinction. Acta Biol Exp (Warsz) 26: 251-258.

Maren S. 2001. Neurobiology of Pavlovian fear conditioning. Annu Rev Neurosci 24: 897-931.

Maren S. 2005. Building and burying fear memories in the brain. Neuroscientist 11: 89-99.

Maren S. 2011. Seeking a spotless mind: extinction, deconsolidation, and erasure of fear memory. Neuron 70: 830-845.

Maren S. 2014. Fear of the unexpected: hippocampus mediates novelty-induced return of extinguished fear in rats. Neurobiol Learn Mem 108: 88-95.

Maren S, Phan KL, Liberzon I. 2013. The contextual brain: implications for fear conditioning, extinction and psychopathology. Nat Rev Neurosci 14: $417-428$

Milad MR, Quirk GJ. 2012. Fear extinction as a model for translational neuroscience: ten years of progress. Annu Rev Psychol 63: 129-151.

Milad MR, Rauch SL, Pitman RK, Quirk GJ. 2006. Fear extinction in rats: implications for human brain imaging and anxiety disorders. Biol Psychol 73: 61-71.

Miller RR, Escobar M. 2002. Associative interference between cues and between outcomes presented together and presented apart: an integration. Behav Processes 57: 163-185.

Miracle AD, Brace MF, Huyck KD, Singler SA, Wellman CL. 2006. Chronic stress impairs recall of extinction of conditioned fear. Neurobiol Learn Mem 85: 213-218.

Morris RW, Furlong TM, Westbrook RF. 2005a. Recent exposure to a dangerous context impairs extinction and reinstates lost fear reactions. J Exp Psychol Anim Behav Process 31: 40-55.

Morris RW, Westbrook RF, Killcross AS. 2005b. Reinstatement of extinguished fear by beta-adrenergic arousal elicited by a conditioned context. Behav Neurosci 119: 1662-1671.

Myers KM, Ressler KJ, Davis M. 2006. Different mechanisms of fear extinction dependent on length of time since fear acquisition. Learn Mem 13: 216-223.

Neumann DL, Longbottom PL. 2008. The renewal of extinguished conditioned fear with fear-relevant and fear-irrelevant stimuli by a context change after extinction. Behav Res Ther 46: 188-206.

Norrholm SD, Jovanovic T, Vervliet B, Myers KM, Davis M, Rothbaum BO, Duncan EJ. 2006. Conditioned fear extinction and reinstatement in a human fear-potentiated startle paradigm. Learn Mem 13: $681-685$.

Pavlov IP. 1927. Conditioned reflexes. Oxford University Press, London.

Polack CW, Laborda MA, Miller RR. 2013. On the differences in degree of renewal produced by the different renewal designs. Behav Processes 99: $112-120$.

Quirk GJ. 2002. Memory for extinction of conditioned fear is long-lasting and persists following spontaneous recovery. Learn Mem 9: $402-407$.

Rachman SJ. 1979. The return of fear. Behav Res Ther 17: 164-165.

Rachman SJ. 1989. The return of fear: review and prospect. Clin Psychol Rev 9: $147-168$.

Raio CM, Brignoni-Perez E, Goldman R, Phelps EA. 2014. Acute stress impairs the retrieval of extinction memory in humans. Neurobiol Learn Mem 112: 212-221.

Rescorla RA. 2001. Experimental extinction. In Handbook of contemporary learning theories (ed. Mowrer RR, Klein SB), pp. 119-154. Erlbaum, Mahwah.

Rescorla RA. 2004. Spontaneous recovery. Learn Mem 11: 501-509.

Rescorla RA, Heth CD. 1975. Reinstatement of fear to an extinguished conditioned stimulus. J Exp Psychol Anim Behav Process 1: $88-96$.

Schiller D, Cain CK, Curley NG, Schwartz JS, Stern SA, LeDoux JE, Phelps EA. 2008. Evidence for recovery of fear following immediate extinction in rats and humans. Learn Mem 15: 394-402.

Siette J, Reichelt AC, Westbrook RF. 2014. A bout of voluntary running enhances context conditioned fear, its extinction, and its reconsolidation. Learn Mem 21: 73-81.

Sigmundi RA, Bouton ME, Bolles RC. 1980. Conditioned freezing in the rat as a function of shock intensity and CS modality. Bull Psychon Soc 15: 254-256.

Urcelay GP, Miller RR. 2014. The functions of contexts in associative learning. Behav Processes 104: 2-12.

VanElzakker MB, Dahlgren MK, Davis FC, Dubois S, Shin LM. 2013. From Pavlov to PTSD: the extinction of conditioned fear in rodents, humans, and anxiety disorders. Neurobiol Learn Mem 113: 3-18.

Vansteenegen D, Vervliet B, Hermans D, Beckers T, Baevens F, Eelen P. 2006. Stronger renewal in human fear conditioning when tested with an 
acquisition retrieval cue than with an extinction retrieval cue. Behav Res Ther 44: 1717-1725.

Vervliet B, Baevens F, Van den Bergh O, Hermans D. 2013a. Extinction, generalization, and return of fear: a critical review of renewal research in humans. Biol Psychol 92: 51-58.

Vervliet B, Craske MG, Hermans D. 2013b. Fear extinction and relapse: state of the art. Аnnu Rev Clin Psychol 9: 215-248.

Westbrook RF, Iordanova M, McNally G, Richardson R, Harris JA.

2002. Reinstatement of fear to an extinguished conditioned stimulus: two roles for context. J Exp Psychol Anim Behav Process 28: 97-110.

Wilson A, Brooks DC, Bouton ME. 1995. The role of the rat hippocampal system in several effects of context in extinction. Behav Neurosci 109: 828-836.

Received September 15, 2014; accepted in revised form January 13, 2015. 


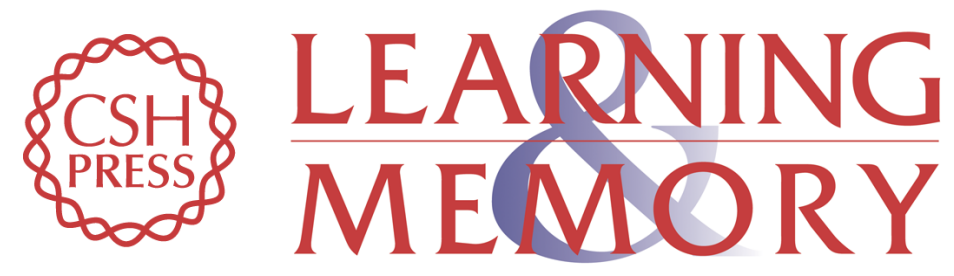

\title{
Relapse of extinguished fear after exposure to a dangerous context is mitigated by testing in a safe context
}

\author{
Travis D. Goode, Janice J. Kim and Stephen Maren
}

Learn. Mem. 2015, 22:

Access the most recent version at doi:10.1101/Im.037028.114

\begin{aligned} & \hline References $\begin{array}{l}\text { This article cites } 77 \text { articles, } 12 \text { of which can be accessed free at: } \\ \text { http://learnmem.cshlp.org/content/22/3/170.full.html\#ref-list-1 }\end{array} \\ & \begin{array}{r}\text { Creative } \\ \text { Commons } \\ \text { License }\end{array} \begin{array}{l}\text { This article is distributed exclusively by Cold Spring Harbor Laboratory Press for the } \\ \text { first } 12 \text { months after the full-issue publication date (see } \\ \text { http://learnmem.cshlp.org/site/misc/terms.xhtml). After } 12 \text { months, it is available under } \\ \text { a Creative Commons License (Attribution-NonCommercial } 4.0 \text { International), as } \\ \text { described at http://creativecommons.org/licenses/by-nc/4.0/. }\end{array} \\ & \begin{array}{c}\text { Receive free email alerts when new articles cite this article - sign up in the box at the } \\ \text { top right corner of the article or click here. }\end{array} \\ & \begin{array}{c}\text { Service } \\ \text { terting }\end{array}\end{aligned}$

